\title{
GESTÃO DO PROCESSO DE PROJETO DE INSTALAÇÕES ELÉTRICAS EM EMPREENDIMENTOS HOSPITALARES: ESTUDO DE CASO
}

\author{
Electrical design management in health \\ care facilities: case study \\ Breno Oliveira', Cícero Starling', Paulo Roberto Andery ${ }^{1}$
}

RESUMO O presente trabalho apresenta um estudo exploratório sobre a gestão do processo de projeto de instalações elétricas em estabelecimentos hospitalares complexos. A pesquisa realizou-se por meio de dois estudos de caso. As fontes de evidências envolveram a documentação de projeto, atas de reuniões, procedimentos, assistência a reuniões de coordenação, entrevistas e acompanhamento de rotinas de trabalho. Dessa forma, foi possível mapear o processo de projeto, identificando problemas, dificuldades e desafios. Os casos, explorados a partir de um referencial teórico que abordou a situação da gestão de projetos e suas diversas disciplinas envolvidas, apresentam um extenso quadro das dificuldades encontradas na elaboração de projetos de instalações elétricas em empreendimentos hospitalares, suas causas e possíveis ações visando minimizar os riscos inerentes a empreendimentos que, por sua natureza, oferecem elevado grau de complexidade e exigem interação completa entre os diversos agentes envolvidos. A ausência de um programa de necessidades adequado, a utilização de técnicas de gestão de projetos ultrapassadas e o desconhecimento técnico das particularidades expostas pelas instalações hospitalares provocam relações tensas entre as partes e, por consequência, o descumprimento dos prazos e a extrapolação dos orçamentos previstos, além de lacunas no atendimento às expectativas de investidores, contratantes e de usuários desses empreendimentos. Por fim, este trabalho aponta a utilização de duas importantes ferramentas com o objetivo de minimizar os riscos apresentados: o programa de necessidades para a elaboração de projetos de instalações elétricas em empreendimentos hospitalares, além de uma sequência proposta para a elaboração dos referidos projetos, fundamentada nos conceitos de gestão do processo de projeto.

PALAVRAS-CHAVE: Gestão do processo de projeto, Instalações elétricas, Empreendimentos hospitalares.

\begin{abstract}
This study aimed to present an exploratory study on the design process management of complex electrical installations in health care facilities. The research was carried out using two case studies. Evidence sources involved the design documentation, minutes of meetings, procedures, coordination meetings assistance, interviews and followup work routines. Thus, it was possible to map the design process, identifying problems, difficulties and challenges. This exploratory study, based in a conceptual framework, highlights design management issues, points out an extensive framework of the difficulties found in the conception of electrical installations designs in health care projects, its causes and enables actions to minimize the risks inherent in projects that, due to its nature, offers high level complexities and requires full interaction between stakeholders. The lack of a proper briefing, the use of outdated management techniques and the technical unfamiliarity about the exposed specialties at hospital facilities cause strained relations between the stakeholders, and therefore delays, cost overruns, in addition to gaps in conforming to expectations of investors, contractors and users. Finally, this study highlights the application of two procedures in an effort to minimize the outlined risks: the briefing for the conception of electrical installations designs in hospital projects, in addition to an electrical design sequence based on design management techniques.
\end{abstract}

KEYWORDS: Design management, Electrical facilities, Hospital projects.

\section{How to cite this article:}

OLIVEIRA B., STARLING C., ANDERY P. R. Gestão do processo de projeto de instalações elétricas em empreendimentos hospitalares: estudo de caso. Gestão e Tecnologia de Projetos, São Paulo, v. 10, n. 2, p. 47-59, jul./dez. 2015 http://dx.doi.org/10.11606/gtp.v10i2.102048

Fonte de financiamento: Declaram não haver Conflito de interesse: Declaram não haver Submetido em: 09 ago. 2015 Aceito em: 14 set. 2015 


\section{INTRODUÇÃO}

Empreendimentos hospitalares demandam projetos que apresentam certo grau de complexidade, devido a suas características únicas dentro do setor de Arquitetura, Engenharia e Construção (AEC). Esta complexidade tem origem em especificações mais restritivas - seja por força de legislação ou por limitações técnicas no que diz respeito à manutenção da vida, de um ou vários pacientes - quando comparadas às encontradas em empreendimentos residenciais, comerciais ou industriais.

No caso de hospitais, observa-se que os modelos arquitetônicos priorizam aspectos funcionais. Por exemplo, os estudos baseados em fluxos hospitalares: primordialmente, as rotas de circulação de pessoas, pacientes, profissionais ou serviços hospitalares. Observa-se certa negligência quanto às instalações em geral, em parte pela ausência de profissionais qualificados nos quadros funcionais das agências ou órgãos reguladores, especialmente no que diz respeito às instalações elétricas.

Instalações elétricas em estabelecimentos assistenciais de saúde (EAS) são especialmente exigentes: demandam redundância em suas fontes de fornecimento de energia elétrica; qualidade de energia e requisitos especiais de isolamento e supervisão das redes. Equipamentos como Grupos Motores Geradores, UPS (Uninterruptible Power Supply), DSI (Dispositivos Supervisores de Isolamento), transformadores isoladores, luminárias protegidas; serviços como fornecimento de energia em tensões diferentes para finalidades específicas e preocupações com equipamentos de grande porte (tais como grandes centrais de climatização) constituem fatores que tornam o projeto das instalações elétricas um dos protagonistas dentre os diversos agentes envolvidos.

A falta de gestão adequada sobre o projeto das instalações elétricas pode acarretar atrasos em cascata, da fase de concepção até a execução dos empreendimentos hospitalares. Para contribuir com este tema, o presente trabalho apresenta um estudo de caso múltiplo com foco na gestão do processo de projeto de instalações elétricas hospitalares, discutindo algumas peculiaridades intrínsecas a este tipo de projeto.

O objetivo da pesquisa foi identificar, a partir dos estudos de caso, particularidades do processo de projeto de instalações elétricas em ambientes hospitalares complexos, analisando em que medida os problemas e desafios reportados na literatura recente sobre o processo de projeto de edificações são verificados nesses ambientes hospitalares complexos. Por outro lado, outro foco de análise diz respeito à interação entre os agentes envolvidos - empreendedor, contratante, gerenciador, projetistas verificando em que medida os mecanismos contratuais impactam na maior ou menor dificuldade de serem criadas formas de trabalho colaborativo em um contexto de projeto simultâneo.

Com base nos estudos de caso e no referencial teórico abordado, são delineadas diretrizes para a melhoria do processo de projeto, em particular no que diz respeito à elaboração do briefing de projetos elétricos, particularmente críticos nesses empreendimentos.

\section{BREVE REFERENCIAL TEÓRICO}

A Gestão do Processo de Projeto (GPP) traz desafios a arquitetos, engenheiros e promotores dos empreendimentos; os principais, porém não únicos, atores presentes no processo. Melhores práticas de gestão são discutidas em todos os níveis da AEC,no entanto frequentemente, de forma isolada (por disciplina), assim como se discute a autoria de um projeto, responsabilidade exclusiva de seu autor (EMMITT, 2010).

É interessante observar a evolução - ou a falta de aplicação prática desta - que afeta a GPP. Em artigo publicado em 1993, intitulado "The 
future for major project management”, Barnes e Wearne (1993) arriscaram, à época, oferecer pontos de vista "futuros" sobre como evoluiria a gestão de projetos, apontando que seus pilares ainda não eram devidamente reconhecidos. Ainda que reconheçam que a efetividade geral da gestão de projetos tenha evoluído, os autores apresentaram desafios que, mais de duas décadas após seu levantamento, ainda persistem, como por exemplo: incompletude de projetos, indefinição sobre os objetivos do empreendimento, ausência de identificação das incertezas do projeto (ou seus riscos), incapacidade de concentrar a tomada de decisões importantes na elaboração do projeto, falta de envolvimento de todos os agentes da cadeia, criação de vários clientes internos e externos em um único projeto, ausência de uma estratégia de contratação e inflexibilidade do responsável pela gestão do projeto em adaptar-se às mudanças ou fatores externos.

No sentido de minimizar estes riscos e suas consequências em projetos, a literatura destaca a importância a ser dada na elaboração do programa de necessidades (ou briefing). Moreira e Kowaltowski (2009) destacam, de forma inequívoca, as fases que compõem o processo de construção de um edifício: o programa, o projeto e sua execução.

A qualidade do produto final depende do rigor e da exigência observados em cada uma dessas fases, pois o subproduto de um processo está diretamente relacionado ao produto anterior, e afetará a qualidade do resultado da fase seguinte. Esta relação pode não ser concluída com a entrega do edifício ao cliente, uma vez que a vida útil de um edifício depende da satisfação do seu usuário em função da adequação da ocupação. Caso haja um desajuste nesta relação, retoma-se o processo de construção para satisfazer as novas condições exigidas ou corrigir os erros observados (MOREIRA; KOWALTOWSKI, 2009).

Além da segregação entre projeto e obra, observa-se também que não há uma unidade entre projetos de diferentes disciplinas. A fragmentação de processos é tema recorrente de críticas em projetos para construção. Nesse sentido, os conceitos de Engenharia Simultânea seguem na direção da necessidade da apresentação de produtos competitivos que não abram mão da personalização ou da exigência da qualidade (FABRICIO, 2002). Portanto, é natural que haja sob a luz da aplicação da Engenharia Simultânea, uma grande sinergia entre o conceito de projeto com seu prazo determinado, necessidade de personalização e expectativas de preenchimento dos mais variados requisitos.

Uma edificação hospitalar compartilha com uma edificação comercial de alto nível necessidades como sistemas elétricos, hidrossanitários, de aquecimento, ventilação, condicionamento de ar, comunicação de dados e proteção contra incêndio, porém, em maior nível de desafios. Além destes, fazem parte do rol de serviços especializados de um hospital: gases medicinais, sistemas de chamada de enfermagem, telemetria, relógios sincronizados, TV a cabo, circuito fechado de TV e, integrando toda esta lista de sistemas, as instalações elétricas. Adicionalmente, um empreendimento hospitalar conta ainda com múltiplas áreas específicas, como salas cirúrgicas, laboratórios, salas de tomografia e radiologia cada qual com seus requisitos especiais quanto a serviços elétricos, de telecomunicações, iluminação, sistemas especiais e de climatização. Hospitais são exemplos dos mais desafiadores tipos de empreendimentos para os quais engenheiros eletricistas podem projetar e instalar energia elétrica, sistemas de comunicações, segurança e sistemas especiais (JUAN, SCHAEFFER; VRENICK, 2010).

Hospitais destacam-se por sua complexidade, pois constituem edifícios que abrigam, além dos pacientes, atividades de ensino e pesquisa, tornando necessária uma estrutura física complexa em termos de exigências arquitetônicas e de projetos complementares (VENEZIA; ONO, 2013). Sendo assim, a configuração presente na qual os projetos das várias disciplinas 
são tratados de maneira linear ou sequencial torna-se particularmente inadequada (CAIXETA, 2011). Considerando-se, portanto, um ambiente que conta com a aplicabilidade de conceitos de Engenharia Simultânea, torna-se essencial a determinação de um diagnóstico da situação atual, no caso de estabelecimentos assistenciais de saúde já existentes (CAIXETA; FABRICIO, 2012) e a formulação criteriosa do programa de necessidades (FONSECA; ABDALLA, 2005; CAIXETA; FABRICIO, 2012; VENEZIA; ONO, 2013); programa esse que seja capaz de traduzir em especificações técnicas exigências funcionais complexas, e que também seja capaz de prever a introdução de novas tecnologias médicas, reduzindo a necessidade de futuras intervenções importantes ao longo do ciclo de vida da edificação.

A publicação da Resolução RDC $\mathrm{n}^{0}$ 50, de 2002 (ANVISA, 2002) apresentou avanços nessa direção. Embora as etapas do processo de projeto definidas na resolução sejam menos detalhadas que as utilizadas na prática por empresas voltadas às incorporações imobiliárias, suas diretrizes ressaltam a importância do estabelecimento do programa de necessidades para as instalações hospitalares (FONSECA; ABDALLA, 2005). Outros autores indicam a conveniência da participação de múltiplos agentes e disciplinas nos estágios iniciais de projeto (LAVY, KISS; FERNÁNDEZ-SOLIS, 2015).

Van Hoof et al. (2015) ressaltam a conveniência de elaborar o programa de necessidades das instalações hospitalares, incluindo nele os requisitos para os projetos elétricos, a partir de um modelo de referência previamente estabelecido. Em particular, os autores propõem o conceito de projeto baseado em evidências para determinar os requisitos de projeto para as instalações, caracterizadas por complexidades dimensionais, tecnológicas e funcionais derivadas - na expressão dos autores, a "filosofia tecnológica" adotada. A partir do conceito de projeto baseado em evidências, propõem um modelo para o processo de projeto.

Em linha similar de raciocínio, Caixeta e Fabrício (2012) apresentam um modelo conceitual para o processo de projeto de requalificação de ambientes hospitalares. O modelo é bastante completo, e seu detalhamento foge do escopo do presente trabalho. Cabe destacar que os autores ressaltam a necessidade de uma cuidadosa investigação inicial dos processos hospitalares, que norteiam as exigências funcionais das instalações. O modelo é composto por quatro grandes etapas, sendo que a etapa específica de desenvolvimento dos projetos é subdividida em três fases: simulação das exigências, avaliação e decisão. Especificamente quanto aos projetos elétricos (tratados no âmbito de projetos complementares), os autores ressaltam a importância de utilização de conceitos de Engenharia Simultânea, de forma que uma equipe multidisciplinar garanta que todas as exigências foram compatibilizadas.

$\mathrm{Na}$ área das instalações elétricas, observa-se que a falta de planejamento, ou até mesmo de uma sequência de trabalho, pode causar muitos problemas em sua execução, afetando de forma importante os prazos de conclusão de projetos. Um caso experimental apresentado por Horman, Orosz e Riley (2006) demonstra uma alta correlação entre o planejamento de uma sequência de trabalho e a produtividade da equipe. Em geral, o gerenciamento de qualquer produto de construção civil deve prestar especial atenção a questões como contratação, gerenciamento de projetos, métodos de construção, controle de projetos, prazos, supervisão da força de trabalho, equipamentos de construção, segurança, tecnologia e comissionamento. Instalações hospitalares constituem estruturas únicas e proprietárias de sistemas complexos, em que tais questões assumem altos níveis de importância e criticidade para o sucesso do empreendimento (LAVY; FERNÁNDEZ-SOLIS, 2010).

Uma gestão de projetos inadequada impacta negativamente tanto na fase de obras quanto na fase de operação de um empreendimento hospitalar. 
Os serviços de manutenção do empreendimento devem ser capazes de garantir, por exemplo, a continuidade do fornecimento de energia elétrica, ou a qualidade da água necessária ao seu funcionamento, a partir de um cadastro do empreendimento que transmita confiança. Para tal, é essencial a existência de um projeto básico de arquitetura atualizado, em conformidade com as atividades desenvolvidas, e aprovado pela Vigilância Sanitária e demais órgãos competentes. Também é necessário garantir que suas instalações prediais de água, esgoto, energia elétrica, gás, climatização, proteção e combate ao incêndio, comunicação e outras existentes atendam às exigências dos códigos de obras e posturas locais, além das normas técnicas pertinentes (AMORIM et al., 2013). Um adequado processo de gestão de projetos potencializa a verificação e consequente validação dessas garantias.

\section{MÉTODO DE PESQUISA}

O trabalho apresenta um estudo de caso múltiplo, seguindo o enfoque metodológico de estudos de caso indicado em Yin (2010). A escolha da metodologia de estudo de caso advém da questão suscitada por esta pesquisa e em consonância com seu objetivo. Em seu livro "Estudo de caso: planejamento e métodos", Yin (2010) pergunta-se: “como saber se devo usar o método de estudo de caso?”, sugerindo adiante que "quanto mais suas questões procuram explicar alguma circunstância presente (por exemplo, ‘como' ou 'por que' algum fenômeno social funciona), mais o método do estudo de caso será relevante”.

A pesquisa englobou, de maneira sintética: a) revisão bibliográfica, com foco na gestão do processo de projeto e projetos de instalações hospitalares; b) definição do foco da pesquisa: análise de particularidades e problemas presentes no processo de projeto de instalações elétricas hospitalares; c) seleção dos empreendimentos objetos do estudo de caso; d) criação de protocolo para os estudos de caso; e) realização de estudo de caso piloto, para validação do protocolo; f) desenvolvimento dos estudos de caso; e g) análise e triangulação dos dados.

Os critérios para seleção dos empreendimentos objeto de estudo foram: a) desenvolvimento de projetos de instalações elétricas; b) acesso às distintas fontes de evidências por parte dos empreendedores; e c) constituírem instalações representativas da realidade de instalações hospitalares.

Como fontes de evidência nos estudos de caso destacam-se: a) toda a documentação relativa aos projetos arquitetônicos e de instalações, em todas as suas fases; b) memoriais de cálculo e/ou descritivos; c) editais de licitações, documentos técnicos e normativos específicos dos empreendimentos estudados; e d) e-mails, correspondência convencional entre as partes e atas de reuniões. Foram também conduzidas entrevistas semiestruturadas com agentes envolvidos no processo de projeto e gestão dos empreendimentos. Maiores detalhes do procedimento metodológico são omitidos por brevidade, e descritos em Oliveira (2015). O Quadro 1 relaciona as principais fontes de evidência e os elementos de análise obtidos das mesmas.

Desta forma, o presente trabalho discute seus resultados baseado em dois estudos de caso, ou em registros momentâneos de um extrato qualificado, lançando mão, neste intuito, de uma análise dos processos de projeto e obras de reforma de dois grandes complexos hospitalares recentemente reformados, localizados em Belo Horizonte (MG).

Por necessidade de síntese, os estudos de caso são apresentados de maneira resumida, omitindo-se o histórico das ações e incidências no processo de projeto, amplamente documentadas em Oliveira (2015). 
Quadro 1. Elementos de análise fornecidos a partir das fontes de evidência utilizadas.

\begin{tabular}{|c|c|}
\hline Fonte de evidência & Elementos de análise fornecidos \\
\hline $\begin{array}{l}\text { Minutas contratuais fornecidas a partir } \\
\text { dos editais de licitações, documentos } \\
\text { técnicos (projetos arquitetônicos e de } \\
\text { instalações, memoriais de cálculo e/ } \\
\text { ou descritivos em todas as fases do } \\
\text { projeto) e normativos específicos dos } \\
\text { empreendimentos estudados }\end{array}$ & $\begin{array}{l}\text { Cruzamento entre as exigências dos contratos } \\
\text { para projetos, seus cronogramas e fluxos, e a } \\
\text { legislação pertinente a contratações públicas, } \\
\text { levantando riscos inerentes à própria atividade } \\
\text { de contratação de projetos em atendimento } \\
\text { a empreendimentos hospitalares e suas } \\
\text { consequências durante os processos de } \\
\text { elaboração destes projetos. }\end{array}$ \\
\hline $\begin{array}{l}\text { Projetos arquitetônicos e de } \\
\text { instalações, memoriais de cálculo e/ } \\
\text { ou descritivos em todas as fases do } \\
\text { projeto }\end{array}$ & $\begin{array}{l}\text { Levantamento das informações técnicas } \\
\text { mínimas necessárias para a elaboração dos } \\
\text { projetos pelas diferentes disciplinas envolvidas, } \\
\text { observando o grau de maturidade dos } \\
\text { processos em suas diferentes fases. }\end{array}$ \\
\hline $\begin{array}{l}\text { E-mails, correspondência } \\
\text { convencional entre as partes e atas de } \\
\text { reuniões }\end{array}$ & $\begin{array}{l}\text { Descrição detalhada da interação entre os } \\
\text { diversos agentes envolvidos; levantamento } \\
\text { das interferências criadas pelas alterações } \\
\text { de escopo ou projetos; exposição de lacunas } \\
\text { decorrentes da ausência de elementos } \\
\text { que compõem um programa de projetos; } \\
\text { interferência de eventos administrativos e/ou } \\
\text { políticos durante os processos de elaboração } \\
\text { dos projetos. }\end{array}$ \\
\hline Entrevistas com os agentes envolvidos & $\begin{array}{l}\text { Delineamento das expectativas em relação } \\
\text { ao processo de projeto; descrição das } \\
\text { dificuldades de comunicação entre as partes; } \\
\text { conhecimento da visão individual de cada } \\
\text { um desses agentes quanto aos problemas } \\
\text { encontrados nos processos e suas soluções, } \\
\text { assim como a percepção dos riscos - previstos } \\
\text { ou não - apresentados durante os processos } \\
\text { dos projetos. }\end{array}$ \\
\hline
\end{tabular}

\section{ESTUDOS DE CASO}

Na sequência são apresentados, de maneira sintética, os resultados dos estudos de caso conduzidos em dois hospitais, denominados "Hospital A" e "Hospital B".

\section{Estudo de caso 1 - Hospital A}

O Hospital A caracteriza-se por ser um hospital de grande porte, constituindo complexo de urgência e emergência implantado no município de Belo Horizonte. Possui área construída de pouco mais de $18.000 \mathrm{~m}^{2}$, oferecendo um número aproximado de 315 leitos. O empreendimento oferece múltiplas especialidades médicas, incluindo terapia intensiva e cirurgias. Do ponto de vista das instalações elétricas, trata-se de um empreendimento completo, que demanda todas as especialidades previstas para as instalações elétricas presentes na normalização vigente.

Por se tratar de obra pública, o projeto de instalações elétricas foi contratado por meio de um processo licitatório elaborado pelo estado de Minas Gerais. O agente público identificou a necessidade de uma ampla reforma no Hospital A, visando sua modernização e ampliação de capacidade em todas as áreas (urgência, emergência, atendimento intensivo e atendimento ambulatorial). Havia ainda a necessidade de atendimento 
à legislação em vigor, em especial aos requisitos presentes na RDC-50 editada pela Anvisa em 2002, pois notificações oriundas de fiscalização por parte da Vigilância Sanitária faziam parte da realidade diária do hospital, reforçando a necessidade de sua adequação. A partir da identificação das necessidades, a administradora do Hospital A desenvolveu, mediante sua equipe própria de arquitetura e engenharia, um projeto arquitetônico básico. Este, somado a uma especificação técnica e um manual de normas para projetos de edificações, compuseram toda a documentação de referência para a elaboração de propostas por parte das empresas de projetos complementares, ou projetos de engenharia de sistemas prediais.

Embora baseado em um planejamento mínimo, observou-se que o processo de projeto de instalações elétricas para o Hospital A não correspondeu a muitas de suas expectativas. Conforme prática recorrente de mercado, a contratação teve um padrão sequencial, com a emissão de um projeto arquitetônico desvinculado das necessidades demandadas pelas instalações elétricas - embora estas não tenham sido as únicas prejudicadas no processo. A ausência de um programa de necessidades que englobasse todo o empreendimento constituiu fator importante para a falta de integração das diversas disciplinas. A elaboração de um projeto arquitetônico de forma individualizada, que não contemplava as principais interferências com as demais disciplinas, atrelada a uma contratação com valores de remuneração fixa que não considerava os diversos pontos de controle necessários ao processo, provocou insegurança no início dos trabalhos de elaboração de projetos de instalações elétricas. Observa-se, pela comunicação entre as partes e atas de reuniões, grande dispêndio de horas para a elaboração de um programa mínimo a ser seguido; horas estas que já consumiam o prazo estabelecido em contrato para o término de todo o processo. Os aditivos de prazo para elaboração de projetos foram, portanto, inevitáveis e, assim, o planejamento sequencial determinado pela empresa pública gestora foi fatalmente atingido.

Apesar das dificuldades, observa-se que a atividade de coordenação e de compatibilização entre os projetos conseguiu, de forma integrada, contornar os problemas encontrados, sobretudo quanto a interferências, porém de forma reativa. É evidente que, caso o processo não tivesse nascido com as dificuldades expostas, um tempo maior poderia ter sido utilizado no estudo e na melhoria de soluções, e não em sua fundamentação.

\section{Estudo de caso 2 - Hospital B}

O Hospital B caracteriza-se por ser um hospital de grande porte, constituindo um complexo de urgência e emergência, também implantado no Município de Belo Horizonte. Possui área construída de aproximadamente $38.000 \mathrm{~m}^{2}$, sendo que até a data de conclusão deste trabalho ainda passava por uma grande reforma, dividida em várias etapas, com o intuito de prover o complexo de um número aproximado de 500 leitos. Diversas especialidades são desenvolvidas no ambiente hospitalar, portanto, assim como o Hospital A, o Hospital B constitui empreendimento completo do ponto de vista das instalações elétricas.

Tratando-se também de empreendimento público e devido à disponibilidade insuficiente de recursos do estado de Minas Gerais, as obras englobaram inicialmente um dos três blocos físicos que compõem a torre principal do empreendimento. A intervenção sobre a qual este trabalho apresenta suas conclusões é produto da segunda e mais complexa obra, que inicialmente abrangeria os outros dois blocos da torre principal, algumas edificações anexas e até mesmo intervenções de ampliação em uma unidade externa, recém-inaugurada à época. As intervenções previstas na unidade externa, embora tenham apresentado certa influência no prazo de conclusão do empreendimento, não compõem esse estudo. 
Diferentemente do Hospital A, o processo de projeto do Hospital B não fez parte de uma contratação única e anterior às obras. Os projetos executivos de engenharia de sistemas prediais compuseram um subitem do contrato de obras, ou seja, a construtora vencedora do certame licitatório era responsável pela elaboração dos projetos executivos de engenharia de sistemas prediais, que seriam embasados nos projetos arquitetônicos fornecidos pela equipe própria de arquitetura e engenharia da empresa cliente.

O processo de projeto do Hospital B transcorreu sob constante tensão entre as partes, pois apresentou em seu desenvolvimento:

- Planejamento equivocado: a iminência de uma data de término das obras pode ter provocado um planejamento cheio de atropelos, originando um empreendimento que contou com a contratação de uma obra permeada de complexidades, sem que esta contasse com projetos em versão executiva. Por se tratar de uma das facilidades previstas para atendimento ao planejamento da cidade de Belo Horizonte com vistas à Copa do Mundo de 2014, o processo sofreu pressões políticas variadas. A situação chegou ao ponto da empresa gestora solicitar a substituição do gerente de contrato designado pela construtora, em meio aos constantes atrasos observados na consecução das metas estabelecidas.

- Ausência de elementos fundamentais: oprojeto arquitetônicomostrouse insuficiente para atender as necessidades do empreendimento, haja vista o grande número e a amplitude das alterações que sofreu. Observou-se que não houve o atendimento a um programa amplamente discutido, baseado em informações adequadas coletadas tanto junto aos usuários do empreendimento (que estavam à disposição, uma vez que se tratava de reforma de empreendimento existente) quanto das demais (e diversas) disciplinas envolvidas. Constatou-se que a comunicação entre usuário e projetista e entre estes e a administração do empreendimento apresentava grandes e graves ruídos. Uma boa gestão da informação, com registros precisos, poderia ter minimizado estas questões.

- Falta de comprometimento de alguns dos projetistas: diversos fatores influenciaram nesta falta de comprometimento, entre elas as indefinições do projeto arquitetônico, causando retrabalho, ausência de elementos para a elaboração de projetos (indefinição de equipamentos, priorização de áreas em detrimento de outras, necessidades de obras provisórias que permitissem o funcionamento do Hospital B durante as obras, que também demandavam projetos técnicos) e desconhecimento de questões técnicas relativas aos empreendimentos hospitalares, esta última razão observada pela empresa contratada, em meio às obras, para realizar a coordenação dos projetos.

Observou-se que, em um momento de maior ansiedade do processo, toda a gestão e planejamento foram abandonados em detrimento de uma força tarefa concentrada na elaboração dos projetos. A falta da correta priorização de etapas no início dos trabalhos forçou uma interrupção das discussões para que os projetos de engenharia de sistemas prediais, a partir de uma arquitetura considerada definitiva, fossem levados a termo, permitindo que a construtora se mobilizasse em definitivo nas áreas que ainda permaneciam sem intervenções. O descumprimento do prazo determinado e do orçamento previsto, mesmo com o corte de importante parte do escopo das obras inicialmente contratadas, atesta o fracasso do planejamento proposto.

\section{DISCUSSÃO}

Songer e Molenaar (1997) apontam os critérios de sucesso para empreendimentos públicos: obediência ao orçamento previsto, atendimento 
às expectativas dos usuários e conformidade com o prazo determinado. Observou-se em ambos os estudos de caso abordados no presente trabalho que os orçamentos foram ultrapassados, as expectativas dos usuários foram negligenciadas (haja vista o grande número de alterações nos projetos considerados finalizados e prontos para o desenvolvimento das etapas posteriores e, no caso do Hospital B, a redução do escopo inicialmente previsto) e os prazos foram descumpridos, com a incidência de diversos aditivos contratuais.

Os problemas descritos nos estudos de caso sugerem que os projetos apresentaram diversas falhas no que diz respeito ao atendimento das expectativas dos agentes envolvidos; expectativas estas que deveriam ser delineadas a partir de um programa de necessidades. Observa-se que este documento, em ambos os casos, foi confundido com especificações técnicas e não atendiam à completude dos projetos, pois eram direcionados somente para a elaboração dos projetos complementares. Mais do que fazer parte da contratação, o programa de necessidades deve ser elaborado na fase de concepção do empreendimento, permitindo inclusive direcionar adequadamente as contratações necessárias. A falta do programa ou, em última análise, a falta de expectativas claras, transformou o processo de projeto de ambos os empreendimentos em uma sequência de problemas a serem contornados, sucessivamente, até que seu término fosse decretado. Não foram estabelecidos previamente quais requisitos os empreendimentos deveriam cumprir, à exceção da técnica fundamental e prazos. Nesse sentido, as conclusões desse trabalho estão em sintonia com as observações da literatura referenciada.

Os estudos de caso permitiram a identificação de onze pontos fracos a serem combatidos na gestão do processo de projeto em empreendimentos hospitalares, apresentados no Quadro 2.

Quadro 2. Identificação de pontos fracos em processos de projetos em empreendimentos hospitalares.

\begin{tabular}{|l|}
\hline 1. Ausência de um programa de necessidades. \\
\hline 2. Contratos a valores fixos e irreajustáveis. \\
\hline 3. Contratação pelo critério de "menor preço" e não "preço e técnica". \\
\hline 4. Ausência de projetos executivos antes do início da execução das obras. \\
\hline 5. Ausência de exigências de qualificação ou especialização técnica dos projetistas. \\
\hline $\begin{array}{l}\text { 6. Concepção arquitetônica desconectada das exigências das demais disciplinas } \\
\text { envolvidas. }\end{array}$ \\
\hline 7. Ausência da prévia especificação dos equipamentos médicos hospitalares. \\
\hline 8. Ausência de pontos de controle multidisciplinares. \\
\hline 9. Ausência de projetos aprovados em órgãos reguladores. \\
\hline 10. Interferências extratécnicas. \\
\hline $\begin{array}{l}\text { 11. Ausência de um marco de término do empreendimento, oferecendo a oportunidade } \\
\text { de retroalimentação aos agentes envolvidos. }\end{array}$ \\
\hline
\end{tabular}

Embora se tratem de empreendimentos da iniciativa pública, não se observa na principal legislação do setor que dispõe sobre as licitações - a Lei 8.666/1993 (BRASIL, 1993) - limitações para que as contratações sigam critérios conhecidos, por exemplo, na Engenharia Simultânea, que poderiam minimizar consideravelmente os riscos inerentes à falta de integração entre as disciplinas. Na esfera política, fragmentada em ciclos de apenas quatro anos, a compactação e sequenciamento forçado das diversas atividades (como identificação das necessidades, planejamento, contratação e elaboração de projetos básicos e executivos, contratação e execução das obras, culminando no evento de inauguração) constitui grande entrave 
para a melhoria do processo de contratação de empreendimentos de grande porte, especialmente hospitalares.

Esta realidade exige a presença do coordenador de projetos, o profissional multidisciplinar com visão holística do empreendimento, capaz de reunir e distribuir as informações certas para os devidos agentes, em tempo hábil, e com a capacidade de organizar o desenvolvimento do projeto, estabelecendo marcos alcançáveis e que obedeçam às expectativas do empreendimento. A coordenação de projetos (e não somente a figura do coordenador) deve ser capaz de prover a visão do empreendimento como um todo, preenchendo as lacunas decorrentes da visão segmentada e estritamente contratual dos diversos agentes envolvidos.

No tocante às instalações elétricas, o responsável pela elaboração do projeto deve verter esforços para que o conceito do projeto elétrico (alimentadores principais, alimentação da concessionária, grupos geradores ou outros meios de geração de emergência, prumadas elétricas e salas técnicas) seja inicialmente discutido e aprovado em detrimento aos demais processos (distribuição de pontos de iluminação, tomadas, telecomunicações, telessinalização, supervisão e automação predial, entre outros) que, mesmo que consumam maior tempo e mão de obra, suas interferências com as demais disciplinas são geralmente de baixo impacto. Processos que envolvam a alteração ou novas redes alimentadoras por parte da concessionária são longos e sem previsão precisa para término, envolvendo instalações de valor significativo, além de diversas interferências arquitetônicas.

Não obstante todas as questões técnicas expostas anteriormente, observam-se em ambos os casos estudados o descompasso entre as importantes definições referentes às instalações elétricas e a concepção arquitetônica dos empreendimentos hospitalares. Observou-se que a contratação das obras públicas nas modalidades realizadas provocou, já na concepção, um sistema de elaboração de projetos de forma sequencial, pois, o projeto arquitetônico e as especificações técnicas já compunham o "programa" do empreendimento. Se devidamente aplicados, conceitos de integração e multidisciplinaridade propostos pela Engenharia Simultânea contribuiriam significativamente para processos com melhor interface entre os diversos agentes envolvidos, determinando requisitos e expectativas mais perenes em relação à utilização e ao ciclo de vida do empreendimento do que tão somente o menor valor de contratação e o prazo determinado para o término das obras.

A análise destes problemas e a identificação de seus pontos fracos permitiram, em conjunto com a literatura existente, a elaboração de diretrizes para melhorias da gestão do processo de projetos em empreendimentos hospitalares, descritas no Quadro 3.

Quadro 3. Diretrizes para melhorias da gestão do processo de projetos em empreendimentos hospitalares.

\begin{tabular}{|c|}
\hline $\begin{array}{l}\text { stas por consultores experientes e com } \\
\text { dos requisitos dos clientes em um adequado } \\
\text { do cliente, a definição de interlocutores } \\
\text { a clara e inequívoca por suas áreas de influência }\end{array}$ \\
\hline $\begin{array}{l}\text { Estabelecimento de formas de contratação que estimulem as partes a buscar resultados } \\
\text { para o empreendimento que sejam revertidos em resultados para suas próprias } \\
\text { organizações. }\end{array}$ \\
\hline
\end{tabular}


Quadro 3. Continuação...

\begin{tabular}{|c|}
\hline $\begin{array}{l}\text { Concepção multidisciplinar, promovendo a integração entre projeto e produto e } \\
\text { permitindo o planejamento prévio das ações. A efetividade deste planejamento } \\
\text { depende da experiência dos agentes envolvidos e flexibilidade no trato multidisciplinar } \\
\text { do empreendimento, minimizando riscos inerentes ao processo. }\end{array}$ \\
\hline $\begin{array}{l}\text { Envolvimento prévio de órgãos reguladores. Aprovações em órgãos reguladores são } \\
\text { morosas, portanto não há como abrir mão de análises prévias junto a estes órgãos, com } \\
\text { o intuito de obter uma pré-aprovação do conceito do projeto proposto. }\end{array}$ \\
\hline $\begin{array}{l}\text { Envolvimento e negociação prévia com fornecedores de equipamentos médico- } \\
\text { hospitalares e/ou de grande porte, permitindo a elaboração de um programa mínimo de } \\
\text { requisitos para a instalação destes. }\end{array}$ \\
\hline $\begin{array}{l}\text { Exigência contratual de obediência aos pontos ou marcos de controle multidisciplinar, } \\
\text { ressaltando claramente a parcela de remuneração para a atividade. Tais marcos não } \\
\text { devem se restringir à participação em reuniões e disponibilidade de horas técnicas, mas } \\
\text { também devem englobar a elaboração de detalhamentos e projetos executivos. }\end{array}$ \\
\hline $\begin{array}{l}\text { Constituição de uma coordenação de projetos proativa, capaz de estabelecer metas } \\
\text { que excedam o simples cumprimento de orçamentos e prazos, buscando resultados } \\
\text { que vão além dos ganhos financeiros, com atendimento aos requisitos do cliente. O } \\
\text { planejamento elaborado deve ser adequado, de forma que os marcos desejados sejam } \\
\text { alcançados, não somente representando metas burocráticas. }\end{array}$ \\
\hline $\begin{array}{l}\text { Registro formal de todas as ocorrências e comunicações trocadas entre os agentes } \\
\text { envolvidos no projeto de forma a permitir, ao final do processo, a realização de uma } \\
\text { reunião como marco de término do projeto que gere como resultado uma "memória de } \\
\text { projeto", descrevendo os problemas encontrados e suas soluções. }\end{array}$ \\
\hline $\begin{array}{l}\text { Emissão do cadastro final do empreendimento (documentos as-built). Ressalta-se que } \\
\text { desenhos (ou documentos) as-built não podem ser considerados projetos, mas sim } \\
\text { cadastros da real execução das instalações. }\end{array}$ \\
\hline
\end{tabular}

Prazos não cumpridos e orçamentos extrapolados demonstram, em ambos os casos estudados, as principais consequências da falta de planejamento adequado dos empreendimentos.

\section{CONCLUSÕES}

O presente trabalho pretendeu analisar especificidades do processo de projeto de instalações elétricas em ambientes hospitalares complexos, à luz de dois estudos de caso. Particularidades do processo de projeto foram identificadas, ressaltando-se a necessidade de maior atenção às etapas inicias do processo de projeto, envolvendo o briefing e o planejamento do projeto. Nesse sentido, os objetivos da pesquisa parecem ter sido alcançados.

A análise dos empreendimentos hospitalares selecionados demonstra que décadas de estudos da gestão do processo de projeto, realizados tanto no Brasil quanto no exterior, ainda não foram devidamente absorvidos pelo mercado em nosso país, particularmente no que diz respeito às obras empreendidas pelo setor público. Observa-se que os gestores insistem em processos sequenciais, mais onerosos e desgastantes quando comparados a processos que apliquem técnicas de eliminação de desperdícios (a exemplo da Lean Construction) ou com a integração entre projeto e produção observada na aplicação da Engenharia Simultânea.

Os contratos estabelecidos não são sensíveis às necessidades de empreendimentos complexos como os hospitalares, sendo a situação ainda mais grave quando se observam as instalações elétricas. Estas, repletas de especificidades, se mal planejadas podem afetar significativamente o prazo e o orçamento previstos para o projeto. Os atuais modelos de contrato, portanto, devem ser modificados, de forma a prever a atuação 
do projetista em todas as etapas do processo, de sua concepção ao início da operação.

Os interessados em atuar no setor de empreendimentos hospitalares devem procurar se especializar e conhecer as demandas únicas destes empreendimentos que envolvem, na maioria dos casos, a manutenção da vida de indivíduos vulneráveis. Estes empreendimentos exigem grande interação entre as diversas disciplinas presentes, sendo a boa técnica apenas um requisito mínimo para o seu sucesso. A ausência de um programa de necessidades adequado às expectativas de um empreendimento hospitalar é crucial para o acirramento das relações entre as partes envolvidas, além de não propiciar os corretos requisitos aos quais o empreendimento deve atender. A indefinição dos requisitos a serem seguidos provoca a ocorrência de solicitações de aditivos de prazo ou remuneração por serviços inicialmente não previstos, fazendo que os gestores corram o risco de verem inacabados os empreendimentos propostos.

\section{REFERÊNCIAS}

AGÊNCIA NACIONAL DE VIGILÂNCIA SANITÁRIA. Resolução de Diretoria Colegiada - RDC $n \div$ 50, de 21 de fevereiro de 2002.

AMORIM, G. M.; QUINTÃO, E. C. V.; JÚNIOR, H. M.; BONAN, P. R. F. Prestação de Serviços de Manutenção Predial em Estabelecimentos Assistenciais de Saúde. Ciência \& Saúde Coletiva, v. 18, n. 1, p. 145158, 2013. DOI: http://dx.doi.org/10.1590/ S1413-81232013000100016.

BARNES, M.; WEARNE, S. The Future for Major Projects Management. International Journal of Project Management, v. 11, n. 3, p. 135-142, 1993. DOI: 10.1016/02637863(93)90046-P.

BRASIL. PRESIDÊNCIA DA REPÚBLICA. Lei no 8.666 de 21 de 1993. Diário Oficial da União, 22 de junho de 1993.

CAIXETA, M. C. B. F. Processo de projeto: Intervenções em Edifícios de Saúde. Dissertação (Mestrado em Arquitetura e Urbanismo) - Instituto de Arquitetura e Urbanismo, Universidade de São Paulo, 2011.

CAIXETA, M. C. B. F.; FABRICIO, M. M. A Conceptual Model for the Design Process of Interventions in Healthcare Buildings: a Method to Improve Design. Architectural Engineering and Design Management, v. 8, p. 1-15, 2012. DOl: 10.1080/17452007.2012.738040.

EMMITT, S. Design Management in Architecture, Engineering and Construction: Origins and Trends. Gestão \& Tecnologia de Projetos, v. 5, n. 3, p. 27-37, nov. 2010. DOI: $10.4237 / g t p . v 5 i 3.173$

FABRICIO, M. M. Projeto Simultâneo na Construção de Edifícios. Tese (Doutorado). Escola Politécnica, Universidade de São Paulo, São Paulo, 2002.
FONSECA, A.; ABDALLA, G. A Resolução RDC No 50 e Suas Interferências no Processo de Projeto. In: SIMPÓSIO BRASILEIRO DE GESTÃO E ECONOMIA DA CONSTRUÇÃO (SIBRAGEC), 4. Anais... Porto Alegre, 2005.

HORMAN, M. J.; OROSZ, M. P.; RILEY, D. R. Sequence Planning for Electrical Construction. Journal of Construction Engineering and Management, p. 363-372, abr. 2006. DOl: http://dx.doi.org/10.1061/ (ASCE)0733-9364(2006)132:4(363).

JUAN, S.; SCHAEFFER, G. J.; VRENICK, S. M. Lean Constructability in Hospital Electrical Projects. Health Facilities Management, $p$. 21-25, jun. 2010.

LAVY, S.; FERNÁNDEZ-SOLIS, J. Complex Healthcare Facility Management and Lean Construction. Health Environments Research \& Design Journal, v. 3, n. 2, p. 3-6, 2010. DOI: $10.1177 / 193758671000300201$.

LAVY, S.; KISS, C. W.; FERNÁNDESSOLIS, J. Linking Design and Energy Performance in US Military Hospitals. Architectural Engineering and Design Management, v. 11, n. 1, p. 41-64, 2015. DOI: 10.1080/17452007.2013.775104

MOREIRA, D. C.; KOWALTOWSKI, D. C. C. K. Discussão Sobre a importância do Programa de Necessidades no Processo de Projeto em Arquitetura. Ambiente Construído, v. 9, n. 2, p. 31-45, abr./jun. 2009

OLIVEIRA, B. A. Gestão do Processo de Projeto de Instalações Elétricas em Empreendimentos Hospitalares. Dissertação (Mestrado em Construção Civil) - Escola de Engenharia da Universidade Federal de Minas Gerais, abr. 2015

SONGER, A. D.; MOLENAAR, K. R. Project Characteristics for Successful Public-Sector Design Build. Journal of Construction Engineering and Management, n. 123, p. 34- 
40, mar. 1997. DOI: http://dx.doi.org/10.1061/ (ASCE)0733-9364(1997)123:1(34).

VAN HOOF. J.; RUTTEN, P. G. S.; STRUCK, C.; HUISMAN, E. R. C. M.; KORT, H. S $M$. The Integrated and Evidence-based Design of Healthcare Environments. Architectural Engineering and Design Management, v. 11, n. 4, p. 243-263, 2015. DOI: 10.1080/17452007.2014.892471.

VENEZIA A. G.; ONO, R. Aplicação de Método de Análise de Risco Visando o
Aprimoramento da Segurança Contra Incêndio no Decorrer do Processo de Projeto de Hospitais de Grande Porte. Gestão \& Tecnologia de Projetos, São Paulo, v. 8, n. 2, p. 89-103, jul./dez. 2013. DOI: $\quad$ http://dx.doi.org/10.11606/gtp. v8i2.68274.

YIN, R. K. Estudo de caso: planejamento e métodos. Tradução Ana Thorell. Revisão técnica Cláudio Damacena. 4. ed. Porto Alegre: Bookman, 2010. 248p.

\author{
Breno Oliveira \\ brenosnato@gmail.com \\ Cícero Starling \\ cicerostarling@ufmg.br \\ Paulo Roberto Andery \\ pandery@ufmg.br
}

